Journal of Alloys and Compounds, 536S1 (2012) 9-12

http://dx.doi.org/10.1016/j.jallcom.2011.11.084

\title{
Comparison of equivalent ball milling processes on Fe70Zr30 and Fe70Nb30
}

\author{
J.S. Blázquez ${ }^{*}$, J.J. Ipus, C.F. Conde, A. Conde
}

Dpto. Física de la Materia Condensada. ICMSE-CSIC. Universidad de Sevilla. P.O. Box 1065. 41080-Sevilla (Spain)

\begin{abstract}
Dynamical analysis of the movement of a single ball in a planetary ball mill yields a cubic law with the frequency of the mill for the power released during the process. This fact has been explored for two binary compositions: $\mathrm{Fe}_{70} \mathrm{Zr}_{30}$ and $\mathrm{Fe}_{70} \mathrm{Nb}_{30}$ using two different milling frequencies. The experimental techniques used, in general, support the predictions of the equivalent milling time model. However, some deviations appear which could be ascribed to differences in the temperature inside the vial during milling.
\end{abstract}

Keywords: Ball milling; amorphous alloys; metastable alloys.

*Corresponding author: J. S. Blázquez

Departamento de Física de la Materia Condensada. Universidad de Sevilla.

Apartado 1065, 41080 Sevilla (Spain).

Phone: (34) 9545560 29/ Fax: (34) 954612097

E-mail: jsebas@us.es 
Journal of Alloys and Compounds, 536S1 (2012) 9-12

http://dx.doi.org/10.1016/j.jallcom.2011.11.084

\section{$1 \quad$ Introduction}

High energy ball milling is a very suitable technique for the production of metastable systems. Particularly, mechanical alloying processes can yield the formation of amorphous alloys in a different compositional range to that obtained by rapid quenching techniques [1]. However, although results from very different mills can be found in the literature, a comparison between them is not simple. Several attempts have been done to estimate the energy release during ball milling processes $[2,3]$. Recently, it has been shown that the power released during milling is proportional to the cubic power of the rotational frequency in planetary ball mills [4]. This leads to a definition of an equivalent milling time $t_{e q}=t \cdot\left(\Omega / \Omega_{0}\right)^{3}$, where $t$ is the milling time, $\Omega$ is the rotational frequency of the mill and $\Omega_{0}$ is a reference frequency. This model has been successfully applied to compare the evolution of different properties of powder obtained at different milling intensities [4,5].

In this work, two different binary alloys have been produced by mechanical alloying at two different milling frequencies, $\Omega_{1}=286$ and $\Omega_{2}=360 \mathrm{rpm}$, such that $\left(\Omega_{2} / \Omega_{1}\right)^{3}=2$. The cubic law predicts equivalent milling products after a double milling time at $286 \mathrm{rpm}$ than at 360 rpm.

\section{Experimental}

Two compositions, $\mathrm{Fe}_{70} \mathrm{Nb}_{30}$ and $\mathrm{Fe}_{70} \mathrm{Zr}_{30}$, were prepared by ball milling of elemental powders in a planetary mill Fritsch Pulverisette Vario 4 using hardened steel balls and vials. The initial powder mass was $5 \mathrm{~g}$ and the ball to powder ratio was 10:1. Two different rotational speeds of the main disk $(\Omega)$ were used: 286 and $360 \mathrm{rpm}$, which present the relationship $\left(\Omega_{1} / \Omega_{2}\right)^{3}=2$. The ratio between the rotational speeds of the vials and the main disk 
Journal of Alloys and Compounds, 536S1 (2012) 9-12

http://dx.doi.org/10.1016/j.jallcom.2011.11.084

was -2. Manipulation of the powders was done under argon atmosphere in a Saffron glove box. After continuous milling periods of $4 \mathrm{~h}$ at $360 \mathrm{rpm}(8 \mathrm{~h}$ at $286 \mathrm{rpm})$, milling was stopped and approximately the same amount of sample $\sim 0.2 \mathrm{~g}$ was extracted in argon atmosphere for each composition. This process was done six times and, in the following, they will be named as milling steps from 1 to $6(4,8,12,16,20$ and $24 \mathrm{~h}$ milling at $360 \mathrm{rpm}$ and 8, 16, 24, 32, 40 and $48 \mathrm{~h}$ milling at $286 \mathrm{rpm}$, respectively). At the first milling step no powder could be recover for the $\mathrm{Zr}$ alloy but the starting material stuck on the ball and vial surfaces forming a shiny layer.

Samples were analyzed using differential scanning calorimetry (DSC) in a PerkinElmer DSC7; X-ray diffraction (XRD) using $\mathrm{Cu}-\mathrm{K} \alpha$ wavelength, scanning electron microscopy (SEM) in a Jeol JSM-6460 LV and Mössbauer spectrometry (MS) in a transmission geometry using a ${ }^{57} \mathrm{Co}(\mathrm{Rh})$ source. Values of the hyperfine parameters were obtained by fitting with NORMOS program [6]. The isomer shift, $I S$, was quoted relative to the Mössbauer spectrum of an $\alpha-F e$ foil at room temperature.

\section{$3 \quad$ Results and discussion}

Figure 1 shows the XRD patterns of several samples. The amorphous phase of the asmilled samples is evidenced by a broad amorphous halo. Figure 2 shows the DSC scans at 40 $\mathrm{K} / \mathrm{min}$ of the different studied samples. All the features observed in the curves are irreversible as they disappear in a second scan, which was used as the corresponding baseline. A general agreement can be found for the two samples of each composition obtained at the same milling step. This is especially clear concerning the broad exothermic peak ascribed to the release of the energy stored during milling (structural and strain relaxation phenomena at low temperatures and grain growth and crystallization phenomena at high temperatures). For all 
Journal of Alloys and Compounds, 536S1 (2012) 9-12

http://dx.doi.org/10.1016/j.jallcom.2011.11.084

the samples, a deviation from the baseline occurs about $400 \mathrm{~K}$ which coincides with a slight decrease of the mass of the sample observed by thermomagnetic gravimetry, TG (both experiments, DSC and TG were performed under argon flow). Thus this feature should be ascribed to some gas desorption from the powders.

However, concerning endothermic processes some differences arise between the two set of experiments performed at different frequencies and depending on the studied composition. For $\mathrm{Nb}$ alloy, there is an endothermic peak about $625 \mathrm{~K}$ which appears only for the samples milled at $360 \mathrm{rpm}$. Similar endothermic peaks were found in FeGeNb powders being ascribed to solving intermetallic(s) formed during milling process [7].

For $\mathrm{Zr}$ alloys, there is an endothermic peak about $950 \mathrm{~K}$ which is enhanced in the samples milled at $286 \mathrm{rpm}$ with respect to the samples milled at $360 \mathrm{rpm}$ (similar smaller peaks are also observed in $\mathrm{Nb}$ alloys at higher temperatures). In this case, the endothermic peak is more suitable to be due to oxidation phenomena. In fact some peaks of the XRD pattern of Zr alloy milled 6 steps and heated up to $993 \mathrm{~K}$ (Fig. 1) could be indexed as magnetite. Moreover, after heating the sample up to $993 \mathrm{~K}$, the mass of the sample increases $0.01 \%$. For the $\mathrm{Nb}$ alloys the oxidation effect is not so clear although some deviations from the baseline can be also detected at high temperatures. On the one hand, $\mathrm{Zr}$ is more reactive than $\mathrm{Nb}$, and, on the other hand, SEM images (figure 3) show a larger average powder particle size, $d$, and a broader distribution for Nb samples $(d=29.1 \pm 2.3 \mu \mathrm{m}, \sigma=12.6 \mu \mathrm{m}$ and $d=23.7 \pm 1.3 \mu \mathrm{m}, \sigma=8.1 \mu \mathrm{m}$ for samples milled 6 steps at 286 and $360 \mathrm{rpm}$, respectively) than for $\mathrm{Zr}$ alloy $(d=10.5 \pm 0.4 \mu \mathrm{m}, \sigma=4.2 \mu \mathrm{m}$ and $d=12.3 \pm 0.6 \mu \mathrm{m}, \sigma=4.2 \mu \mathrm{m}$ for samples milled 6 steps at 286 and $360 \mathrm{rpm}$, respectively).

An expected difference between two equivalent milling processes is the temperature inside the vial during the milling process. Initially, the temperature inside the vial increases 
Journal of Alloys and Compounds, 536S1 (2012) 9-12

http://dx.doi.org/10.1016/j.jallcom.2011.11.084

till an stationary regime is reached when the heating produced inside the vial due to ball collisions (proportional to $\Omega^{3}$ ) equals the heat losses (proportional to the difference between temperatures inside and outside the vial, $\Delta \mathrm{T}$ ), thus $\Delta \mathrm{T}=\mathrm{k} \Omega^{3}$. This behavior was checked by measuring the temperature of the outside wall of the vial after $30 \mathrm{~min}$ milling at different frequencies using a thermocouple. Figure 4 shows the predicted linear behavior.

In the case of $\mathrm{Nb}$ alloy, the formation of the intermetallic should be temperature dependent and the temperature reached at $286 \mathrm{rpm}$ should be not high enough for it. In the case of Zr alloy, oxidation will be enhanced for smaller grains as the surface to volume ratio increases.

Crystallization DSC peaks are not very clear due to overlapping with oxidation phenomena, although it can be detected close to $900 \mathrm{~K}$ for $\mathrm{Zr}$ alloys milled at $360 \mathrm{rpm}$.

Figure 5 shows MS spectra for several studied samples. Spectra of Nb alloys were fitted using two contributions: a single sextet with hyperfine field, HF $\sim 33 \mathrm{~T}$, representing the residual $\alpha$-Fe phase (not detected after the $3^{\text {rd }}$ milling step) and a quadrupolar distribution to describe the non-magnetic amorphous phase. Spectra of $\mathrm{Zr}$ alloys were fitted using three contributions: a single sextet with hyperfine field, $\mathrm{HF} \sim 33 \mathrm{~T}$, representing the residual $\alpha$-Fe phase, a distribution of hyperfine fields from 0 to $20 \mathrm{~T}$ and a quadrupolar distribution.

In order to compare the spectra corresponding to equivalent milling steps, for each velocity, the recorded values at $360 \mathrm{rpm}$ were plotted versus those recorded at $286 \mathrm{rpm}$ and the regression coefficient are shown in table 1 along with some relevant fitting results. The contribution used with $\mathrm{HF} \sim 33 \mathrm{~T}$ corresponds to residual $\alpha$-Fe phase. As the area fraction of this phase decreases, HF decreases due to $\mathrm{Zr}$ or Nb solution and crystal size refinement. The non magnetic contribution increases as milling progresses and corresponds to the non 
Journal of Alloys and Compounds, 536S1 (2012) 9-12

http://dx.doi.org/10.1016/j.jallcom.2011.11.084

magnetic amorphous phase detected by XRD being the isomer shift roughly in agreement with those reported for $\mathrm{Fe}_{70} \mathrm{Zr}_{30}$ [8] and $\mathrm{Fe}-\mathrm{Nb}$ intermetallics [9]. Concerning the quadrupolar splitting, $\Delta$, the values of the parameter $q=\left\langle\Delta^{2}\right\rangle|<\Delta\rangle^{2}$, are 1.5 for both alloys, in agreement with Pizarro et al. for FeZr [8]. However, this value is higher than those corresponding to Czjzek distributions in the frame of random packing of hard spheres model [10]. The third contribution used in $\mathrm{Zr}$ alloy corresponds to a magnetic phase which could be $\mathrm{Fe}_{2} \mathrm{Zr}$ or $\mathrm{Fe}_{3} \mathrm{Zr}$ formed in an earlier stage of the milling process and which fraction decreases as milling progresses in the studied range.

\section{Conclusions}

In this work amorphous binary alloys were produced by mechanical alloying using two equivalent milling processes. The microstructure and thermal stability agree with the predicted equivalent time model based on the cubic frequency dependence of the energy released during milling processes by ball collisions.

Deviations found could be ascribed to differences in the temperature inside the vial during milling. The behavior of this temperature can also be predicted by the same cubic frequency law.

\section{Acknowledgements}

This work was supported by the Spanish Ministry of Science and Innovation (MICINN) and EU FEDER (project MAT2010-20537) and the PAI of the Regional Government of Andalucía (project FQM-6462). 
Journal of Alloys and Compounds, 536S1 (2012) 9-12

http://dx.doi.org/10.1016/j.jallcom.2011.11.084

Table 1: Regression coefficients between spectra of samples milled at 286 and $360 \mathrm{rpm}$.

Hyperfine parameters: $\mathrm{HF}_{\mathrm{X}}, \mathrm{IS}_{\mathrm{X}}$ and $\mathrm{A}_{\mathrm{X}}$, hyperfine field, isomer shift and area fraction of residual $\alpha-F e$ phase; $\mathrm{HF}_{\mathrm{M}}, \mathrm{IS}_{\mathrm{M}}$ and $\mathrm{A}_{\mathrm{M}}$, average hyperfine magnetic field, isomer shift and area fraction of $\mathrm{HF}$ distribution; $\Delta$ and $\mathrm{IS}_{\mathrm{Q}}$, average isomer shift and quadrupolar splitting of the quadrupolar distribution. Values appear as $\mathrm{a} / \mathrm{b}$, being $\mathrm{a}$ and $\mathrm{b}$ the corresponding values at 286 and $360 \mathrm{rpm}$, respectively.

\begin{tabular}{|c|c|c|c|c|c|c|c|c|c|c|c|}
\hline $\mathrm{Fe}_{70} X_{30}$ & step & $\mathbf{r}$ & $\begin{array}{c}\mathbf{H F}_{\mathbf{X}} \\
(\mathrm{T})\end{array}$ & $\begin{array}{c}\mathrm{IS}_{\mathbf{X}} \\
(\mathrm{mm} / \mathbf{s})\end{array}$ & $\begin{array}{c}\mathbf{A}_{\mathbf{X}} \\
(\%)\end{array}$ & $\begin{array}{c}\mathbf{H F}_{M} \\
(\mathbf{T})\end{array}$ & $\begin{array}{c}(-) I S_{M} \\
(\mathbf{m m} / \mathbf{s})\end{array}$ & $\begin{array}{c}\mathbf{A}_{\mathbf{M}} \\
(\%)\end{array}$ & $\begin{array}{c}\Delta \\
(\mathrm{mm} / \mathrm{s})\end{array}$ & $\begin{array}{c}(-) I S_{Q} \\
(\mathrm{~mm} / \mathbf{s})\end{array}$ & $\frac{\langle\Delta\rangle^{2}}{\left\langle\Delta^{2}\right\rangle}$ \\
\hline \multirow{12}{*}{$\mathrm{X}=\mathrm{Nb}$} & \multirow{2}{*}{1} & \multirow{2}{*}{0.990} & $32.7 /$ & $0.01 /$ & $48 /$ & & & & $0.48 /$ & $0.16 /$ & $1.7 /$ \\
\hline & & & 32.3 & 0.04 & 36 & & & & 0.46 & 0.16 & 1.6 \\
\hline & \multirow{2}{*}{2} & \multirow{2}{*}{0.9994} & $31.9 /$ & $0.04 /$ & $17 /$ & & & & $0.41 /$ & $0.17 /$ & $1.5 /$ \\
\hline & & & 31.6 & 0.06 & 15 & & & & 0.43 & 0.17 & 1.5 \\
\hline & \multirow{2}{*}{3} & \multirow{2}{*}{0.998} & $30.0 /$ & $0.08 /$ & $15 /$ & & & & $0.47 /$ & $0.17 /$ & $1.6 /$ \\
\hline & & & 31.3 & 0.10 & 8 & & & & 0.41 & 0.17 & 1.5 \\
\hline & \multirow{2}{*}{4} & & & & & & & & $0.46 /$ & $0.16 /$ & $1.6 /$ \\
\hline & & 0.99 & & & & & & & 0.43 & 0.16 & 1.5 \\
\hline & \multirow[t]{2}{*}{5} & \multirow{2}{*}{0.9995} & & & & & & & $0.42 /$ & $0.17 /$ & $1.5 /$ \\
\hline & & & & & & & & & 0.45 & 0.16 & 1.5 \\
\hline & \multirow{2}{*}{6} & \multirow{2}{*}{0.9993} & & & & & & & $0.39 /$ & $0.17 /$ & $1.5 /$ \\
\hline & & & & & & & & & 0.42 & 0.16 & 1.5 \\
\hline \multirow{8}{*}{$\mathrm{X}=\mathrm{Zr}$} & 2 & 0.996 & $32.5 /$ & $0.05 /$ & \multirow[t]{2}{*}{$6 / 7$} & \multirow[t]{2}{*}{$7.5 / 6.3$} & \multirow[t]{2}{*}{$0.18 / 0.05$} & $59 / 58$ & $0.54 /$ & $0.13 /$ & $\begin{array}{l}1.5 / \\
1.5\end{array}$ \\
\hline & \multirow[b]{2}{*}{3} & \multirow{2}{*}{0.9992} & $\begin{array}{l}32.6 \\
32.3 /\end{array}$ & $\begin{array}{l}0.06 \\
0.06 /\end{array}$ & & & & \multirow[b]{2}{*}{$21 / 23$} & $\begin{array}{l}0.45 \\
0.40 /\end{array}$ & $\begin{array}{l}0.22 \\
0.18 /\end{array}$ & $\begin{array}{l}1.5 \\
1.5 /\end{array}$ \\
\hline & & & 32.4 & 0.04 & $6 / 6$ & $4.8 / 5.2$ & $0.02 / 0.01$ & & 0.38 & 0.17 & 1.5 \\
\hline & \multirow{2}{*}{4} & \multirow{2}{*}{0.9996} & $32.4 /$ & $0.03 /$ & \multirow{2}{*}{$5 / 4$} & \multirow{2}{*}{$5.8 / 5.6$} & \multirow{2}{*}{$0.02 / 0.03$} & \multirow{2}{*}{$17 / 18$} & $0.40 /$ & $0.16 /$ & $1.5 /$ \\
\hline & & & 32.4 & 0.05 & & & & & 0.41 & 0.17 & 1.5 \\
\hline & \multirow{2}{*}{5} & 09994 & $32.4 /$ & $0.07 /$ & $5 / 8$ & $5.0 / 5.5$ & $0.02 / 0.04$ & $16 / 22$ & $0.42 /$ & $0.17 /$ & $1.5 /$ \\
\hline & & & 31.5 & 0.07 & & & & $10 / 22$ & 0.43 & 0.17 & 1.5 \\
\hline & 6 & 0.9998 & $32.4 /$ & $0.10 /$ & $5 / 6$ & $5.2 / 5.5$ & $0.04 / 0.05$ & $18 / 19$ & $0.42 /$ & $0.17 /$ & $1.5 / 1.5$ \\
\hline
\end{tabular}


Journal of Alloys and Compounds, 536S1 (2012) 9-12

http://dx.doi.org/10.1016/j.jallcom.2011.11.084

\section{Figure captions}

Figure 1. XRD patterns of several studied samples.

Figure 2. DSC plots of the different studied samples.

Figure 3. SEM images of both alloys milled 6 steps at 286 and $360 \mathrm{rpm}$.

Figure 4. Linear dependence of $\Delta \mathrm{T}$ with $\Omega^{3}$.

Figure 5. Mössbauer spectra of several studied samples. The contributions used to fit are also shown. 
Journal of Alloys and Compounds, 536S1 (2012) 9-12

http://dx.doi.org/10.1016/j.jallcom.2011.11.084

Figure 1

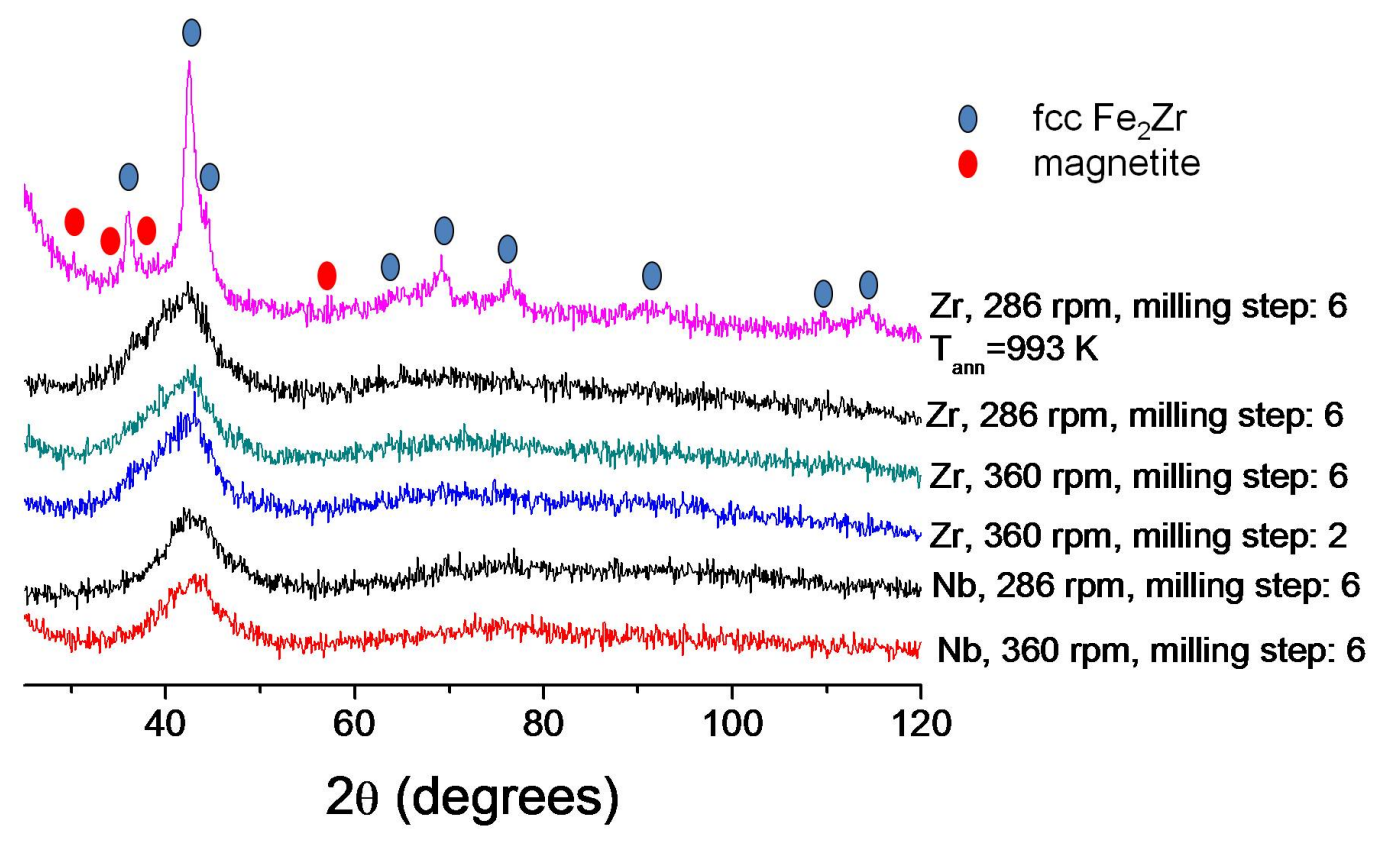


Journal of Alloys and Compounds, 536S1 (2012) 9-12

http://dx.doi.org/10.1016/j.jallcom.2011.11.084

Figure 2

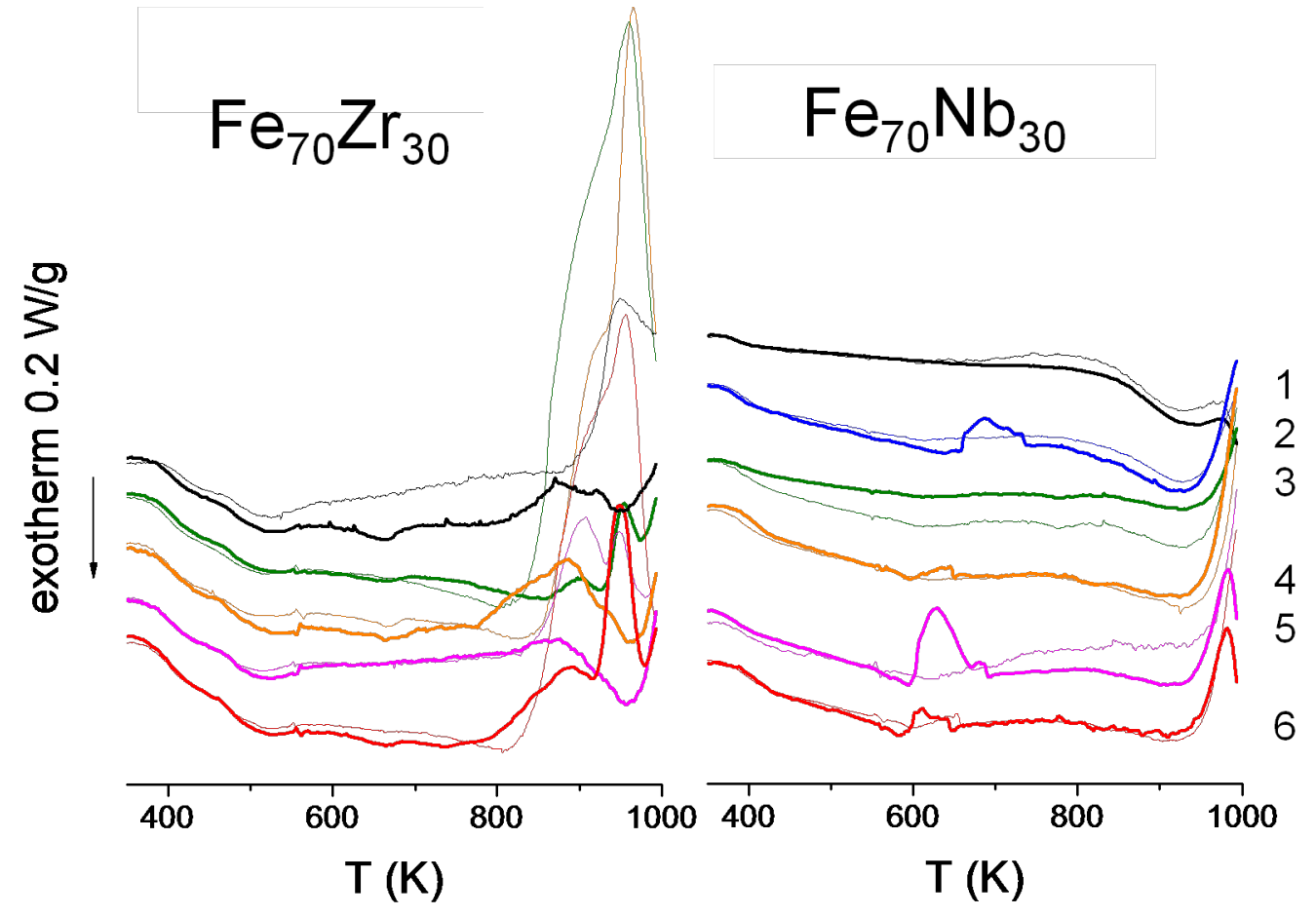


Journal of Alloys and Compounds, 536S1 (2012) 9-12

http://dx.doi.org/10.1016/j.jallcom.2011.11.084

Figure 3

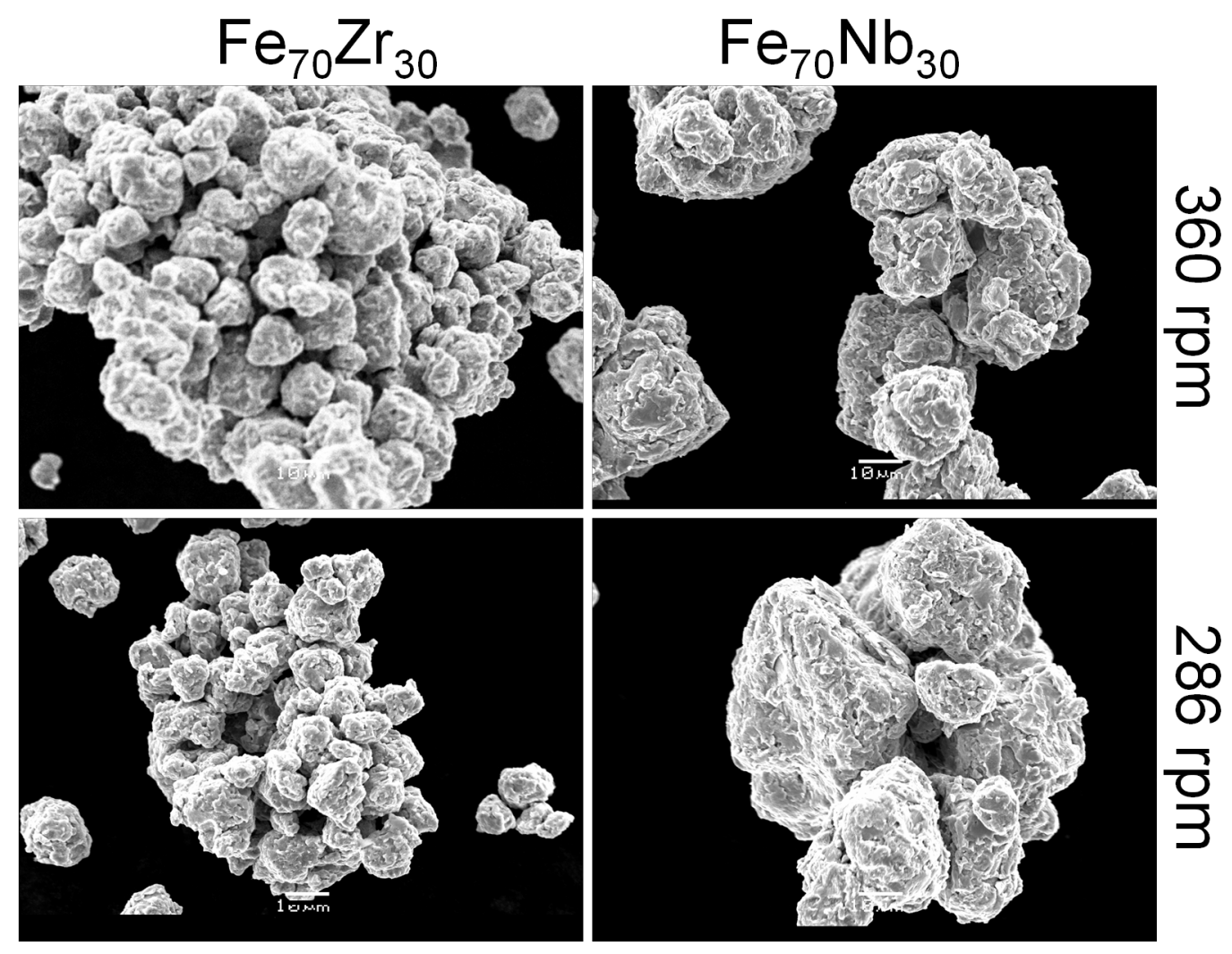


Journal of Alloys and Compounds, 536S1 (2012) 9-12

http://dx.doi.org/10.1016/j.jallcom.2011.11.084

Figure 4

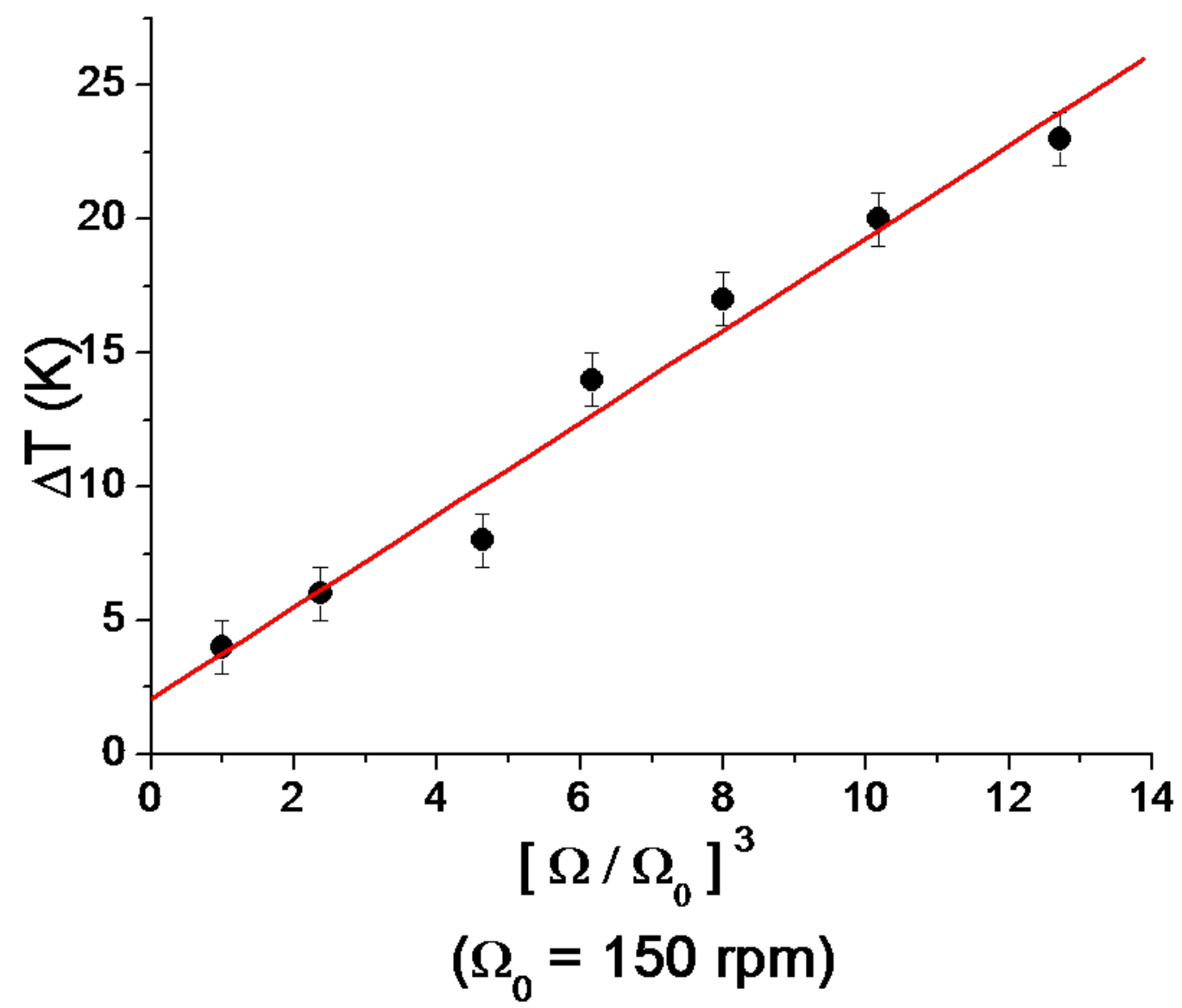


Journal of Alloys and Compounds, 536S1 (2012) 9-12

http://dx.doi.org/10.1016/j.jallcom.2011.11.084

Figure 5

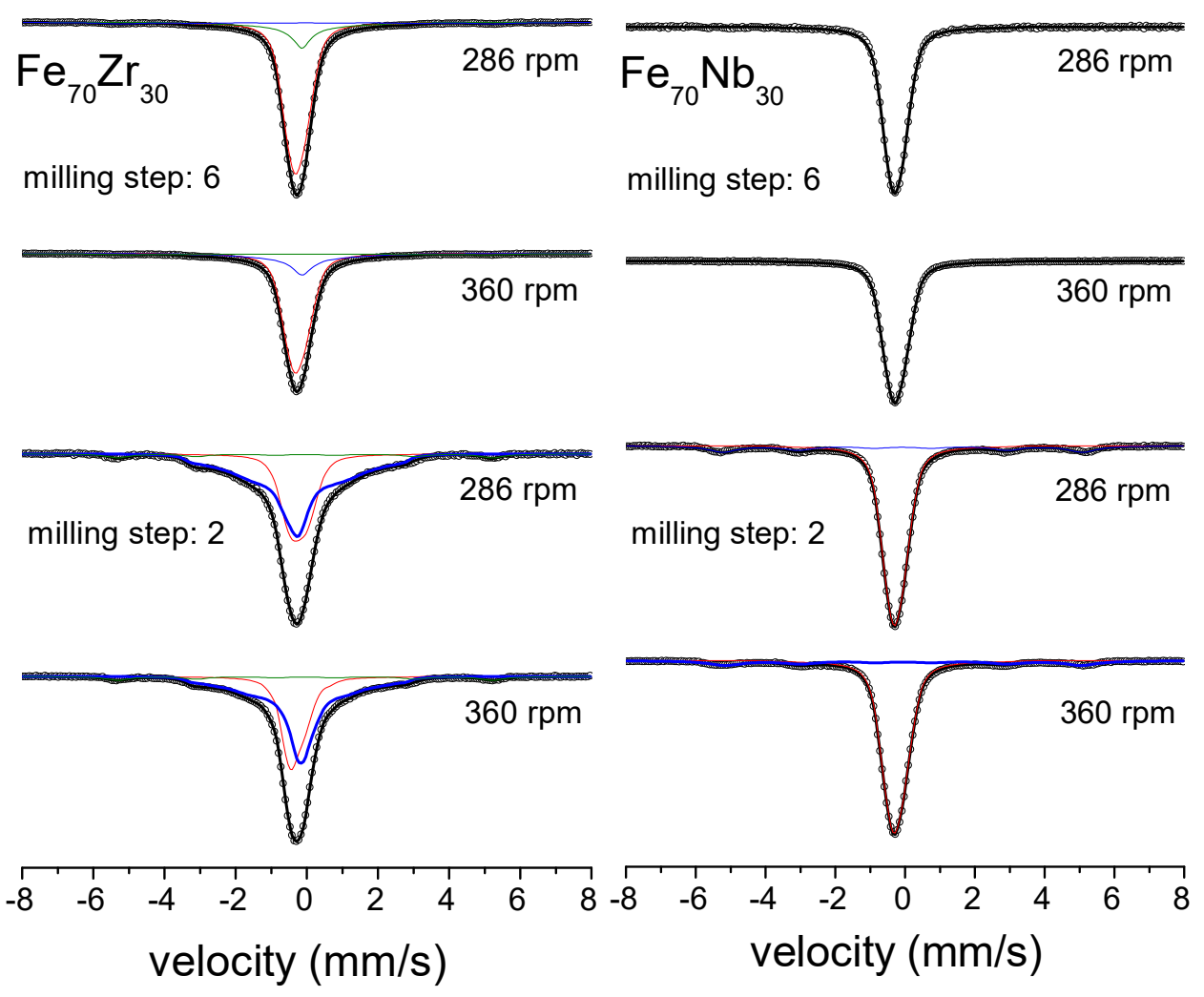


Journal of Alloys and Compounds, 536S1 (2012) 9-12

http://dx.doi.org/10.1016/j.jallcom.2011.11.084

\section{References}

[1] L. Schultz, Mat. Sci. Eng. 97 (1988) 15-23.

[2] M. Abdellaui, E. Gaffet, Acta Metall. Mater. 43 (1995) 1087-98

[3] M. Magini, A. Iasonna, Mater. Trans. JIM 36 (1995) 123-133.

[4] J. J. Ipus, J. S. Blázquez, V. Franco, M. Millán, A. Conde, D. Oleszak, T. Kulik, Intermetallics 16 (2008) $470-478$

[5] J. J. Ipus, J. S. Blázquez, V. Franco, A. Conde, L. F. Kiss, J. Appl. Phys. 105 (2009) 123922.

[6] R. A. Brand, J. Lauer, D. M. Herlach, J. Phys. F: Met. Phys. 13 (1983) 675.

[7] J. S. Blázquez, J. J. Ipus, M. Millán, V. Franco, A. Conde, D. Oleszak, T. Kulik, J. All. Comp. 469 (2009) 169-178.

[8] R. Pizarro, J. S. Garitaonandia, F. Plazaola, J. M. Barandiarán, J. M. Greneche, J. Phys. Cond. Matter 12 (2000) 3101-3112.

[9] A. M. Van Der Kraan, K. H. J. Buschow, Physica B 138 (1986) 55-62.

[10] G. Czjzek, J. Fink, F. Götz, H. Schmidt, J. M. D. Coey, J. P. Rebouillar, A. Lienard, Phys. Rev. B 23 (1981) 2513. 